Bol. Acad. peru. leng. 67. 2020 (103-137)

\title{
DIEGO MEXÍA DE FERNANGIL: CUATRO SIGLOS DE UN LIBRO SIN EDITAR
}

\section{DIEGO MEXÍA DE FERNANGIL: FOUR CENTURIES OF AN UNEDITED BOOK}

\author{
María de Fátima Salvatierra \\ Universidad Nacional Mayor de San Marcos \\ maria.salvatierra@unmsm.edu.pe \\ https://orcid.org/0000-0002-2552-3217
}

$\mathrm{Al}$ doctor Luis Jaime Cisneros, in memoriam

\begin{abstract}
Resumen:
El presente artículo trata sobre el único manuscrito de la obra de Diego Mexía de Fernangil, titulada La segunda parte del Parnaso Antártico de divinos poemas (1617), que se encuentra en la Biblioteca Nacional de Francia, inédita hasta la fecha. Se describen los estudios y ediciones parciales que se han hecho del texto, se señala su importancia, y se propone su edición paleográfica y modernizada.
\end{abstract}

Palabras clave: Diego Mexía de Fernangil, poesía peruana, siglo XVII, edición. 
Abstract:

This article is about on the unique manuscript of the work by Diego Mexía de Fernangil entitled La segunda parte del Parnaso Antártico de divinos poemas (1617) [Antarctic Parnassus, Part Two: Poems of the Divine], which is located in the National Library of France, unpublished until now. It describes the studies and partial editions that have been made of the text, points out its importance, and proposes its palaeographic and modernized edition.

Key words: Diego Mexía de Fernangil, Peruvian poetry, 17th century, edition.

Fecha de recepción:

Fecha de aceptación:
$12 / 02 / 2020$

$25 / 04 / 2020$

Diego Mexía de Fernangil fue hijo legítimo de Diego Mexía de Fernangil y de Juana de Cabrera, según figura en un testamento (Quisbert Condori, 2011: 270). Nació en Sevilla, pero no se ha podido determinar su fecha de nacimiento.

Alrededor de 1593 ya se encontraba en Lima, donde se dedicó a diferentes actividades comerciales. Al respecto, Juan Gil afirma que Diego Mexía de Fernangil debía de ser «una persona joven y vigorosa» (Gil, 2008: 69) para poder realizar todos los viajes que implicaba su trabajo mercantil en el extenso virreinato peruano (anduvo por Lima, México, Potosí). Negociaba diferentes productos, entre ellos, libros (tal como su padre lo hacía en España), y también fue inversionista, o lo que modernamente se conoce con el nombre de bróker (Gil, 2008: 77). En esta actividad financiera, también participaba su esposa, doña María de Miranda, joven extremeña de Zafra con quien se casó el 13 de agosto de 1590.

La vida literaria de Diego Mexía de Fernangil estuvo ligada a la Academia Antártica (bajo el seudónimo de Delio), publicó una obra en su natal Sevilla: la Primera parte del Parnaso Antártico (1608); quedó manuscrita 

https://doi.org/10.46744/bapl.202001.004

e inédita La segunda parte del Parnaso Antártico. Se desconoce, hoy en día, el paradero de la supuesta tercera parte, que el poeta manifestó ya tenerla lista en la dedicatoria al príncipe de Esquilache: «con la begninidad que espero embiaré La tercera parte, donde | terná U ex.a no la menor en sus dignissimas alabanças» (fol. fv. ${ }^{\circ}$.

En Potosí, también se relacionó activamente con la intelectualidad de la época, por ejemplo, con los León Pinelo, con los españoles nobles y ricos de la cofradía de la Santa Vera Cruz y con los del Santo Oficio. Además, debió interactuar con otros destacados escritores del lugar.

Murió en enero de 1634 en Potosí (Quisbert Condori, 2011: 267) aunque no está precisado el día exacto en los documentos que obran sobre su defunción.

\section{Diego Mexía de Fernangil y el Humanismo}

Valbuena Prat afirma que «el humanista de la generación de Felipe II revestía un aspecto escriturario y teólogo, junto al conocimiento de las antigüedades clásicas» (1960: 575). Diego Mexía de Fernangil personifica esta caracterización en La segunda parte del Parnaso Antártico de divinos poemas, en la que aparece el hombre religioso y doctrinario (fue «ministro del Santo Oficio de la Inquisición, en la visita y corrección de los libros») y también se encuentra el escritor que transporta la tradición grecolatina a su poesía. Diego Mexía de Fernangil incorporó a la literatura peruana estos dos elementos fundamentales de su formación humanista, pero les otorgó un matiz particular de crítica social respecto al entorno en que les tocó vivir.

Diego Mexía de Fernangil no solo desarrolló el aspecto religioso en La segunda parte del Parnaso Antártico, sino también incluyó temas e intereses teológicos en «El discurso en loor de la poesía» de la Primera parte del Parnaso Antártico (1608). Estos temas también están presentes en muchas otras piezas literarias de los más representativos miembros de la Academia Antártica.

El otro punto de la formación humanista de Diego Mexía de Fernangil, alusivo a su «conocimiento de las antigüedades clásicas» (Valbuena 
Prat, 1960: 575), tan presente en La segunda parte del Parnaso Antártico, ha sido extensamente estudiado también en la Primera parte del Parnaso Antártico por Juan Gil en su trabajo titulado «Diego Mexía de Fernangil, un perulero humanista en los confines del mundo» (2008).

\section{Las primeras menciones del texto}

Las primeras noticias que tenemos de La segunda parte del Parnaso Antártico provienen del propio autor, en el siglo xvir. No se volvería a hablar de esta obra hasta el siglo XIX cuando José Toribio Medina la encontró en la Biblioteca de París. Luego, muchos estudiosos la han examinado. Veamos las principales referencias:

1. 1608: Diego Mexía de Fernangil anunció la segunda parte en la dedicatoria a don Juan de Villela que se encuentra en la Primera parte del Parnaso Antártico, de la siguiente manera: «A quien suplico, que recibiendo esta Primera parte de mis obras amatorias debaxo de su protecion, disponga el animo para acetar la segunda, i a mi por uno de los mas aficionados servidores de v. m.» (1608).

2. 1878: José Toribio Medina, en su Historia de la literatura colonial de Chile, describió la segunda parte en una nota al pie de página cuando comentó la Primera parte del Parnaso Antártico. Transcribimos la cita ad pedem literae de la edición de 1878:

${ }^{4}$ La segunda parte del Parnaso Antártico de divinos poemas, dirijida al exelentísimo Príncipe de Esquilache, uirei y capitan jeneral del Perú por el Rei nuestro Señor, por Diego Mexia de Fernangil, ministro del Santo Oficio de la Inquisición en la visita y correccion de los libros, y natural de la ciudad de Seuilla, existe manuscrita en la Bib. Nac. de Paris.

Aludiendo su autor a una de las Empresas y Simbolos que el padre del principe habia publicado en Praga, siendo embajador cerca de Rodulfo $2 .^{\circ}$, y en los cuales se pinta a una nave esperando desaparejada en el puerto que pase el tiempo riguroso del invierno, dice que es lo que mas bien retrata su estado "pues habiendo por espacio de estos ocho años últimos corrido por mis negocios tan deshecha tormenta, que habiendome 
llevado los mas de los bienes que llaman de fortuna, me recoji en esta imperial villa (Potosí) con mi familia como en seguro puerto, esperando pasase el rigor desde airado ivierno, i donde con quietud he gozado de los bienes del entendimiento, sobre quien no tiene la fortuna dominio ni imperio alguno. He desenvuelto muchos autores latinos, $\mathrm{i}$ he frecuentado los umbrales del templo de las sagradas musas».

Se compone esta segunda parte de doscientos sonetos sobre la vida del Cristo, i su historia es la siguiente: el padre jesuita Jerónimo Natal publicó una vida de J. C ilustrándola con ciento cincuenta i tres estampas, «las cuales habiendo venido a mis manos en esta villa Imperial de Potosí, cebado de la variedad i elegancia de las imájenes, comencé con atencion i devocion a remirar i contemplar los pasos de aquella soberana vida de nuestra vida, i vi que desde la Encarnacion deste piadosísimo Redemptor todo fue nuestro i para nosotros. I allí arrebatado en su amor, en agradecimiento de tantas mercedes con mi tosca i mal limada musa me dispuse a consagrar a cada estampa un soneto castellano». Mandé, agrega Mexia, el año pasado de catorce a España los sonetos «puestos en la mayor perfeccion que pude» para que pasasen a imprimirse a Amberes i se acompañasen en un solo cuerpo de las estampas».

«No ignoro, añade, que los sonetos no son para seguir hilo de alguna historia, por ser un jénero de compostura que dispone i remata un concepto cabalmente con suma perfeccion»; i despues reconoce tambien que en la parte en que ha podido ir con más libertad sin sujetarse a la tarea de la esplicacion de las estampas, su pluma ha corrido mas fácil. «No digo esto por escusar mis ignorancias; antes confieso que tengo muchas para tan alta empresa, i conozco que en 33 años que ha salí de España es ya otro el lenguaje i otra la perfeccion i altura de la poesía, pero con esta que entonces traje i acá se ha disminuido, quise hacer este servicio a aquel Señor que estimó en mas el cornadillo de la pobrecita que las magníficas ofrendas de los ricos i poderosos... Es esta mi poesía como los ídolos que Alcibíades consagraba al dios Sileno que en lo exterior eran feos i mal compuestos i dentro de sí encerraban joyas i piedras preciosas, i ningunas de mas valor ni estima que las obras de Cristo N. S. Estas son las que te ofrezco para que si el cielo te hubiese concedido el don poético divino, lo emplees en servicio deste gran Señor... i es mui justo que todos los que nos preciamos de cristianos alabemos i engrandezcamos a este Señor tan grande... Nosotros, pues como hijos alabemos su nombre, contemos 
sus hazañas, celebremos su vida i regalémonos con su muerte, i todos en tal sujeto empleen las almas, las lenguas i las plumas, supliendo con la elegancia i artificio de sus metros las muchas faltas de estas mias». El libro tiene 195 fojas en $8^{\circ}$, de letra mui pequeña; está ricamente empastado, con las armas de Esquilache pintadas en una de las primeras pájinas i grabadas en las tapas, i contiene ademas de la vida de Jesucristo, una Epístola a la Serenisísima Reyna de los Anjeles, Santa María Virgen; La Perla de la Vida de Santa Margarita vírgen i mártir, dirijida al licenciado Alonso Maldonado de Torres; una Oracion en alabanza de la Señora Santa Ana; Las Novísimas; una Egloga del Buen Pastor, i otra del Dios Pan al Santisimo Sacramento (1878: 196-97, nota 4).

Esta es una descripción detallada inicial del manuscrito. Posteriormente, Medina repitió esta descripción en su Biblioteca Hispano-americana (1601-1650); además, transcribió el fragmento de una carta fechada el 4 de enero de 1575 sobre los negocios de Mexía en el Cuzco (Medina, 1900: 91).

3. 1892: Alfred Morel-Fatio, en su Catalogue des manuscrits espagnols et des manuscrits portugais, describió el manuscrito como sigue:

599. «La segunda parte del Parnaso antartico de divinos poemas, dirigida al excelentissimo principe de Esquilache, virrei i capitan general del Piru por el Rey nuestro señor, por Diego Mexia de Fernangil, ministro del sancto officio de la inquisicion en la visita y correccion de los libros y natural de la ciudad de Sevilla. Año de 1647» (il y avait d'abord 1617). Dans sa dédicace à D. Francisco de Borja, prince d'Esquilache, l'auteur parle de la première partie du Parnaso antártico, imprimée à Séville en 1608 (voyez P. Salvá, Catálogo, $\mathrm{n}^{\circ}$ 783), et aussi de la troisième partie, qu'il dit être achevée comme la seconde. Cette dédicace est datée de Potosi, 15 janvier 1617, et suivie de la signature autographe de l'auteur. Dans l'avis au lecteur, Mexia explique que les sonnets sur la vie du Christ, qui forment la partie essentielle de ce recueil, avaient été composés dans le principe pour en faire un commentaire aux estampes du père Hieronimo Natal, de la Compagnie de Jésus, puis qu'ayant renoncé à ce projet, il a porté le nombre de ces sonnets de 153 à 200 , et s'est décidé à les faire imprimer séparément. Au f. $j$, se trouve une estampe représentant le Christ. Les fol. 1-101 vo sont occupés par les 

https://doi.org/10.46744/bapl.202001.004

sonnets sur la vie du Christ; le reste du volume (fol. 102-195 v ${ }^{\circ}$ ) est rempli par diverses poésies religieuses, dont trois portent des dédicaces à «Alonso Maldonado de Torres, presidente en la real audiencia de los Charcas, i agora oidor del consexo real de las Indias»; à «Leonor de la Trinidad, fundadora y abbadesa de las monxas descalças de la limpia concepcion del monasterio del sor S. Josef en la ciudad de los Reyes del Piru», et à «Diego de Portugal, del consexo del rey $\mathrm{n}^{\text {ro }} \mathrm{s}^{\text {or }} \mathrm{y}$ su presidente en la real audiencia de los Charcas». Papier. Reliure aux armes des Borja. 209 feuillets. 205 millimètre sur 150. Année 1617.- [Classement de 1860, n. ${ }^{\circ} 389$; Oratoire, n. ${ }^{\circ} 241$ ] (1892: 209)

Actualmente, esta es la reseña que ofrece la Biblioteca Nacional de Francia sobre este códice.

4. 1895: Marcelino Menéndez y Pelayo describió —en una nota al pie de página- este manuscrito de La segunda parte del Parnaso Antártico de divinos poemas en la revista La España Moderna, donde indicó en el inicio que deseaba "subsanar aquí la omisión de la segunda parte». Transcribimos la cita completa:

De Diego Mexía traté en el capítulo concerniente al Perú, de mi Antología de poeta hispano-americanos; pero quiero subsanar aquí la omisión de la segunda parte inédita de su Parnaso Antártico; que se conserva en la Biblioteca Nacional de Paris (número 599 del catálogo de Morel-Fatio). El manuscrito perteneció al virrey principe de Esquilache, cuyas armas lleva, y a quien fue dedicado por el propio Diexo (sic) Mexía de Fernangil, ministro del Santo Oficio de la Inquisición en la visita y corrección de los libros, y natural de la ciudad de Sevilla. El autor residia entonces en la villa de Potosí, después de haber perdido la mayor parte de su fortuna en la «deshecha tormenta que corrió por sus negocios». De todo ello se consolaba con el cultivo de las letras, «desenvolviendo muchos autores latinos y frecuentando los umbrales del sagrado templo de las Musas». "Conozco (añade) que en treinta y tres años que ha sali de España, es ya otro el lenguaje y otra la perfección y alteza de la poesia, pero con esta que entonces traje y acá se ha disminuido, quise hacer este servicio a aquel Señor que estimó en más el cornadillo de la pobrecita que las magnificas ofrendas de los ricos y poderosos... Es esta mi poesia como 
los idolos que Alcibíades consagraba al dios Sileno, que en lo exterior eran feos y mal compuestos, y dentro de si encerraban joyas y piedras preciosas, y ningunas de más valor ni estima que las obras de Cristo Nuestro Señor».

Esta segunda parte, en efecto, es de carácter enteramente distinto de la primera, pues solo contiene versos religiosos. Ocupan la mayor parte del tomo doscientos sonetos sobre la vida de Cristo, escritos con idea de que acompañasen a unas estampas del P. Jerónimo Natal, de la Compañía de Jesus. Después se encuentran una Epístola a la Serenissima Reyna de los Angeles, Santa Maria Virgen; La Perla de la vida de Santa Margarita, Virgen y Martir; dirigida al licenciado Alonso Maldonado de Torres, presidente en la Real Audiencia de las Charcas, y luego oidor en el Consejo de Indias; una Oración en alabanza de la Señora Santa Ana; Las novísimas, una Égloga del Buen Pastor, y otra del Dios Pan al Santisimo Sacramento (1895b: 108-9, [1]).

Menéndez y Pelayo, en su descripción, retoma varias de las citas textuales extraídas del manuscrito que hizo Medina en 1878, a la par que declara que el trabajo de J. T. Medina es «obra de grande erudición, que nos ha sido muy útil en nuestro trabajo» (1895b: 107).

Esta misma descripción se publica, nuevamente, en el mismo año (Menéndez y Pelayo 1895a) y, póstumamente, en el libro Historia de la poesía hispano-americana (1913).

5. 1914: José de la Riva-Agüero, en su disertación $(1914)^{1}$ leída en el Congreso de Historia y Geografía Hispanoamericana, publicada en 1914 y titulada «Diego Mexía de Fernangil, poeta sevillano del siglo XVI, avecindado en el Perú y la segunda parte de su Parnaso Antártico, existente en la Biblioteca Nacional de París», aborda la vida y obra conocidas de Mexía en aproximadamente 43 pá-

1 En la edición de las obras completas de Riva-Agüero, se señala que este mismo estudio se «reprodujo parcialmente posteriormente en la revista Cultura, n. ${ }^{\circ} 1-3$, Lima, junio-agosto 1915. En 1954, con ocasión del X aniversario de la muerte de Riva-Agüero, la revista Histórica (Órgano del Instituto Histórico del Perú, Lima, tomo XXI, pp. 37-75) lo recoge íntegramente con una breve introducción de Raúl Porras Barrenechea (pp. 5-8)» (Pacheco Vélez y Varillas, 1962: 108). 
https://doi.org/10.46744/bapl.202001.004

ginas. Este trabajo podemos dividirlo en tres grandes secciones. En la primera sección, Riva-Agüero reúne la información sobre la vida de Diego Mexía a partir de lo que el mismo poeta cuenta en sus obras. En esa sección cita datos dispersos acerca del autor, por ejemplo, de Arana de Varflora (1791), G. Ticknor (1854), Menéndez y Pelayo (1895a), Mendiburu (1885). Aclara datos biográficos erróneos, cuando lo considera pertinente, deslizados en los diccionarios, compendios, etc. Y describe la primera parte y las relaciones literarias de Diego Mexía de Fernangil con otros poetas de la época.

En la segunda sección de su estudio, Riva-Agüero empieza con la descripción detallada del manuscrito de La segunda parte del Parnaso Antártico. Propone el siguiente esquema: el texto e imágenes de la carátula, la dedicatoria al príncipe de Esquilache (casi completa), los epígrafes en latín, el índice, el prólogo al lector (parcialmente) y fragmentos de la «Introducción» a los sonetos (I. La vida de Cristo).

En la tercera y última gran sección de su valioso estudio, Riva-Agüero transcribe varios poemas y sigue estrictamente el orden propuesto en el manuscrito. Algunos poemas están reproducidos en su totalidad, y otros, solo fragmentariamente. A cada transcripción le acompaña un comentario literario.

En resumen, es un trabajo de inestimable valor, pues hasta ese momento (1914) no había un estudio detenido de esta obra en particular; a pesar de que el manuscrito y su ubicación ya habían sido divulgados por los eruditos del siglo anterior.

\section{Referencias posteriores en artículos, estudios e historias literarias}

Después del análisis de José de la Riva-Agüero (1914), ha habido más trabajos alusivos a La segunda parte del Parnaso Antártico en la crítica literaria peruana y extranjera, de diferente dimensión. Atendiendo a un criterio cronológico, que es el que venimos empleando en esta sección, damos cuenta de los principales. 
https://doi.org/10.46744/bapl.202001.004

1. 1916: Julio Cejador y Frauca, en su Historia de la lengua y literatura castellana, indica que La segunda parte del Parnaso Antártico fue escrita en Potosí y está compuesta de versos religiosos (1916: 271). Tiene como fuente el ya referido estudio de Alfred Morel-Fatio (1892). También cita el título completo del estudio de Riva-Agüero (1914).

2. 1921: El libro de Luis Alberto Sánchez titulado Los poetas de la Colonia y la Revolución tuvo hasta tres ediciones (1921, 1946 y 1974). La que se consultó para el presente trabajo fue la tercera y última edición (1974), la cual incluye las anotaciones de sendas ediciones anteriores (1921 y 1946).

Sánchez, cuando trata sobre La segunda parte del Parnaso Antártico de divinos poemas, continúa los datos proporcionados por Riva-Agüero (1914), como él mismo manifiesta: «Para juzgarla he de atenerme a lo apuntado por Riva Agüero en su ya mencionado estudio» (1974: 69). También, añade que «lo más interesante del manuscrito es la «Epístola y dedicación de la Égloga intitulada el Dios Pan...»» (1974: 69).

En las líneas dedicadas a esta epístola, y refiriéndose a los siguientes versos: «Los cabellos que ayer fueron dorados,/hoy plata son, mañana serán lodo;/y en sempiterno olvido, sepultados»; señala que, además de la intertextualidad del poema «A las ruinas de Itálica», de Rodrigo Caro (1573-1647), ya señalada por Riva-Agüero (1914: 412), están presentes otras fuentes: primero, la oda "Por la victoria de Lepanto», de Fernando de Herrera (Sánchez, 1974: 70); segundo, «los versos del propio Mexía en la epístola de Penélope a Ulises [de la Primera parte del Parnaso Antártico]» (Sánchez, 1974: 70, nota 1).

Luis Alberto Sánchez, en otro de sus reconocidos trabajos titulado La literatura peruana, que tuvo hasta cinco ediciones, refiere muy brevemente (1965: 398) lo ya desarrollado en Los poetas de la Colonia y la Revolución acerca de La segunda parte del Parnaso Antártico de divinos poemas. 
3. 1948: Alberto Tauro del Pino, en su libro Esquividad y gloria de la Academia Antártica (1948: 29, 38), recoge las propuestas de Ventura García Calderón (1938a) y Augusto Tamayo Vargas (1947), en las cuales sostienen que la autora anónima del «Discurso en loor de la poesía» (de la primera parte del Parnaso Antártico) es Leonor de la Trinidad, fundadora y abadesa de las Monjas Descalzas de la Limpia Concepción en Lima, a quien Diego Mexía de Fernangil dirige la «Égloga intitulada el Buen Pastor» en la penúltima sección de La segunda parte del Parnaso Antártico.

4. 1951 y 1953: Luis Jaime Cisneros, en sendos números de la revista Mar del Sur, transcribe los sonetos 146 y 155 (1951: 70) y el soneto de la peroración (1953: 71). Tales sonetos pertenecen a los 202 poemas dedicados a la vida de Cristo, de La segunda parte del Parnaso Antártico. Cisneros manifiesta que el estudio que había emprendido lo llevaría a ubicar a Diego Mexía de Fernangil «entre los místicos españoles, sin duda» (1951: 70).

5. 1953: Augusto Tamayo Vargas, en su Literatura peruana (la primera edición data de 1953-4), dice lo siguiente sobre La segunda parte del Parnaso Antártico:

[...] es ascética, ya que no mística, pues se detiene en la descripción religiosa y no llega a la confusión del alma con Dios. Se indica, sin embargo, cierto plano místico en el soneto 175 , que termina:

¿Por qué me azotas?, ¿porque te he criado?

¿Por qué me enclavas, ¿porque te sustento?

¿Por qué me afrentas, ¿porque te redimo?

Hijo, no más rigor, no más pecado, mi Cruz adora, siente lo que siento, mi muerte estima, pues tu vida estimo. (1968: 256)

Tamayo Vargas apunta que en los poemas sobre la vida de Cristo de Mexía no encontramos «el arrobamiento espiritual sino la «estampa» misma hecha verso» (1968: 256). Por otra parte, señala 
que Diego Mexía de Fernangil emplea recursos verbales semejantes tanto para su traducción de Las Heroidas (Primera parte del Parnaso Antártico) como para los sonetos dedicados a la vida de Cristo y el «Memorare, novísima» (1968: 257).

En cuanto a la «Epístola a la Virgen María», Tamayo Vargas refiere que el uso del terceto revela las influencias de Dante y Cervantes (1968: 257). Y añade que Dante también está presente cuando Diego Mexía de Fernangil recurre al tópico del «viaje hacia el Infierno» ${ }^{2}$ (1968: 257); asimismo, al respecto, afirma que "tres y siete son números cabalísticos de la poesía de Dante» (1968: 257). Otros referentes temáticos, según Tamayo Vargas, son Jorge Manrique, Francois Villón y Garcilaso, el de las Églogas. Aunque, en relación con este último, precisa que los versos de Mexía «tienen más de eruditos y ascéticos, que de pastoriles. Responden a un conocimiento bíblico y a una reminiscencia de Boecio cantando "De consolatione"» (1968: 258).

6. 1959: Manuel Suárez-Miraval, en su libro La poesía en el Perú (1959), al tratar La segunda parte del Parnaso Antártico reseña los comentarios que, en su oportunidad, Riva-Agüero (1914) había hecho. Además, Suárez-Miraval sostiene que «Mexía de Fernangil rebasa el simple parentesco [con Rodrigo Caro y Jorge Manrique] y resulta más lleno de autenticidad de lo que a primera vista pudiera intuirse» (1959: 135). Por ejemplo, para Suárez-Miraval, Mexía de Fernangil «ausculta el estado social del país. Aquí puede encontrarse un lejano antecedente de las informaciones secretas de Jorge Juan y Ulloa» (1959: 137). También, Suárez-Miraval resalta dentro de los «aportes $[\ldots]$ en nuestra poesía, $[\ldots]$ cierta proclividad al empleo de la toponimia. Ya desde esos tiempos el nombre aborigen, de auténtico y pronunciado sabor indígena, por encima del color local, aúpa su eufonía como un elemento de versificación impuesto por el paisaje» (1959: 139).

2 En la «Epístola a la Virgen María», no hay precisamente un viaje al infierno; más bien, se recurre a varias imágenes alusivas al averno para señalar su quebranto debido al nacimiento de la Virgen María. 
https://doi.org/10.46744/bapl.202001.004

7. 1959: En un breve trabajo presentado para el curso de Bibliografía de la Literatura Peruana, dictado en la Escuela Nacional de Bibliotecarios del Perú, titulado «Bio-bibliografía de Diego Mexía de Fernangil», Carmen Ochoa Garzón (1959) reúne puntual información sobre el poeta.

Carmen Ochoa esboza una breve biografía de Mexía en la «Introducción» de su trabajo con los datos que aportan, básicamente, Riva-Agüero y Menéndez Pelayo.

A continuación, reúne en fichas una exhaustiva «Homobibliografía, o sea las obras escritas por el poeta» (Ochoa Garzón, 1959: ii). Luego, igualmente en fichas, acopia una extensa información ordenada cronológicamente y que titula «Heterobibliografía, o sea todo aquello que se ha escrito sobre él» (Ochoa Garzón, 1959: ii). La autora finaliza con sendos índices «onomástico», «titular», "publicaciones periódicas».

Este meritorio trabajo, culminado en 1959 por la entonces estudiante de Bibliotecología Carmen Ochoa, dice haber seguido las normas del Prontuario de técnica bibliográfica, de su maestro Ricardo Arbulú Vargas.

8. 2002: Wáshington Delgado (2002) ubicó la obra de Diego Mexía de Fernangil dentro de los poetas del Renacimiento europeo tardío en América. Describe los sonetos de La segunda parte del Parnaso Antártico como «limpios de estilo y [que] trasuntan emociones verdaderas» (2002: 22). Para el estudioso — coincide con Riva-Agüero (1914)— «El Dios Pan» es «la perla más valiosa» (2002: 23) de esta segunda parte. Finalmente, Delgado transcribe uno de los sonetos donde confirma la influencia de Jorge Manrique y Rodrigo Caro; el poema empieza: «Un siglo viene, pásase volando / nacen mil gentes, muérense mil gentes [...]», y termina en «Los cabellos que ayer fueron dorados / hoy plata son, mañana serán lodo / y en sempiterno olvido sepultados» (2002: 23). 
9. 2005: José Antonio Rodríguez Garrido dedicó un estudio titulado «La égloga El Dios Pan de Diego Mexía de Fernangil y la evangelización en los Andes a inicios del siglo XVII». En este estudio, sostiene:

Diego Mexía de Fernangil no soslayó un asunto central sobre el que reposaba la «legitimidad» de la presencia española en el Nuevo Mundo: el de la evangelización de los indios; pero en lugar de referirlo frontalmente, se sirvió en su égloga titulada El Dios Pan [...] para proponerlo alegóricamente y así tomar claro partido en medio de la polémica sobre los métodos de cristianización en los Andes [...] solo recuperando los contextos de los que dicha pieza [la égloga titulada El Dios Pan] forma parte es posible recomponer adecuadamente su plena significación. (2005: 308)

Rodríguez Garrido sigue un orden para sustentar su interpretación. Primero: «Situar la égloga de El Dios Pan en el conjunto textual mayor del que forma parte (la Segunda parte del Parnaso Antártico)»(2005: 308). Segundo: «Estudiaré [...] el ámbito de recepción al que la obra estaba originalmente dirigida». Tercero: "pondré en relación la égloga con su paratexto inmediato, la "Epístola dedicatoria a don Diego de Portugal"» (2005: 308). Y cuarto: "Intentaré una lectura del texto en relación con el contexto colonial en que se produjo y al que se refiere» (2005: 308). Además, Rodríguez transcribe — para sus ejemplos - algunos versos del manuscrito original, y manifiesta que ha «optado por modernizar la puntuación y la ortografía, respetando, sin embargo, las peculiaridades fonológicas» $\left(2005: 317,\left[{ }^{3}\right]\right)$.

10. 2009: Alicia de Colombí-Monguió, en su estudio titulado «Lecturas paralelas: La musa sagrada en Potosí», manifiesta haber trabajado con una copia del manuscrito parisense de La segunda parte del Parnaso Antártico de divinos poemas: "Agradezco infinitamente al profesor José Antonio Mazzotti la copia del manuscrito que se halla en la Biblioteca Nacional de Francia» (2009: 68, nota 3). 
https://doi.org/10.46744/bapl.202001.004

Su transcripción de algunos poemas es modernizada y, en el caso puntual del soneto 8 , sobre la vida de Cristo, sigue la lección de Riva-Agüero (1914).

En las primeras páginas del mencionado estudio (Colombí-Monguió, 2009: 67-77)3 , la autora realiza un análisis intertextual sobre algunos temas coincidentes de la vida de Cristo, del libro Poesías sagradas (Sevilla, 1612), y de Luis de Ribera, con La segunda parte del Parnaso Antártico de divinos poemas. Luego, su trabajo se centra en la obra y figura de Luis de Ribera.

11. 2010: Paola Coronado-Gálvez publicó en el Boletín Hispánico Helvético un artículo titulado «Diego Mexía de Fernangil, un poeta antártico» (2010: 31-49). Aunque el título es bastante general, la autora se centra en La segunda parte del Parnaso Antártico. Este trabajo presenta cuatro grandes secciones. En la primera, se contextualiza la obra y vida de Diego Mexía de Fernangil dentro de lo que fue el Renacimiento, Manierismo y Barroco peruano. Menciona los temas de interés no solo de Mexía, sino de sus coetáneos (amores, ideales platónicos y misticismo) y las claras influencias de los clásicos (Homero, Virgilio, Marcial, Ovidio, Píndaro, Horacio, Demóstenes, Cicerón, Heródoto, Tito Livio) en las obras de la época.

La segunda parte del artículo está destinada a reunir los datos más actualizados de la biografía de Diego Mexía de Fernangil; para este fin, las fuentes principales a las que acude son José Riva-Agüero (1914), Trinidad Barrera (1990), Juan Gil (2008) y Lohmann Villena (1951 y 1999).

En la tercera parte, se refiere brevemente a la primera y a la tercera parte (aún no ubicada) del Parnaso Antártico, para luego centrarse preferentemente en la segunda parte. Coronado-Gálvez describe La segunda parte del Parnaso Antártico de divinos poemas

3 También ha referido este estudio Vicente Bernaschina (p. 321, nota 7). 
de la siguiente manera: «[...] hace gala de un verso depurado y versátil, pasa del endecasílabo al heptasílabo con gracia rítmica; emplea el soneto, la lira, el romance para hablar de temas religiosos basándose en textos bíblicos con notable empleo de giros lingüísticos y profundas metáforas, con expresa riqueza de razonamientos conceptistas» (2010: 35).

Coronado-Gálvez cita a Morel-Fatio (1892) y a José de la Riva-Agüero (1914) en la descripción del manuscrito. No precisa si trabajó directamente con el manuscrito o con una reproducción de este, pero observa:

El texto de la Segunda Parte del Parnaso Antártico ha sido escrito o copiado por una sola persona. Las escasas correcciones muestran que no se trata de un borrador, ni de un original, sino de una copia. Por el momento, es imposible afirmar que se trate de una copia autógrafa, a pesar de encontrar en la Dedicatoria dirigida al Príncipe de Esquilache, virrey del Perú, una firma supuestamente de Diego Mexía de Fernangil. (2010: 36-37)

Luego, describe detalladamente el tema y el estilo de cada una de las partes de la obra. También, resume las estrofas y las funciones que cumplen estas en la obra del poeta, por ejemplo, el soneto, los tercetos endecasílabos, las octavas reales, la lira, versos sin rima, la égloga y los villancicos.

La cuarta parte está centrada en la descripción de la égloga «El Buen Pastor», sobre la cual apunta temas, personajes, métrica, estilo. Y, concluye en lo siguiente:

Este análisis de la «Égloga intitulada El Buen Pastor» refleja la evolución del estilo naturalmente poético de su autor, que progresivamente va del asunto religioso al mitológico con un ritmo renacentista, pero con interesantes razonamientos bajo un léxico no místico, aunque sí evidencia un acercamiento a los textos bíblicos. (2010: 42) 
Al final del artículo, ofrece una transcripción de esta misma égloga (2010: 43-47), acompañada de una imagen del manuscrito con el título y la dedicatoria de la obra.

12. 2015: Bernat Castany, en su estudio titulado «Ovidio transformado». La presencia de Ovidio en las dos primeras partes del «Parnaso Antártico» de Diego Mexía de Fernangil», indica una serie de similitudes entre las dos obras de Diego Mexía y Ovidio: las coincidencias temáticas, versificación, poéticas, etc. Castany, cuando se detiene en el examen de La segunda parte del Parnaso Antártico, hace alusión directa a los folios del manuscrito para citar los poemas que le sirven al sustentar sus afirmaciones, que en unos casos ya han sido publicados pero en otros aún no (Castany Prado, 2015: 66-84).

13. 2019: Vicente Bernaschina Schürmann, en su libro titulado Ángeles que cantan de continuo. La legitimación teológica de la poesía en el virreinato del Perú, propone la dedicatoria que precede a la égloga «El Dios Pan» (2019: 217-227), la misma égloga «El Dios Pan» (2019: 230-233) y algunos de los sonetos de la vida de Cristo (2019: 351-353) de La segunda parte del Parnaso Antártico como parte del corpus de textos que le permiten sustentar lo siguiente:

Hipótesis de este estudio es que la legitimación teológica de la poesía culta en el virreinato del Perú es una estrategia poética y política mediante la que los letrados buscan instituir a la poesía como una formación discursiva, que les permita doctrinar sobre la civilidad cristiana que ha de garantizar la realización práctica de una sociedad católica en el virreinato del Perú. En este sentido, la poesía se pliega a la ideología cristiana que legitima al poder monárquico e interpela desde allí a todos los súbditos de la Monarquía con el fin de regular sus comportamientos y prácticas en conformidad con los principios ejemplares de un sujeto católico. (Bernaschina Schürmann 2019: 31)

Para las citas de los poemas, usa las publicaciones parciales de Riva-Agüero (1914), Ricardo Silva Santisteban (1984) y Rubén Vargas Ugarte (1943). 
https://doi.org/10.46744/bapl.202001.004

14. 2019: En el sitio electrónico (Proyecto Estudios Indianos s. f.) de la Universidad del Pacífico, que reúne en una colección digital varios libros de los siglos XVI, XVII y XVIII, encontramos un enlace al repositorio digital de la Biblioteca Nacional de Francia, a través del cual podemos acceder a la lectura del manuscrito. Además, hay algunas figuras seleccionadas de este y el referido estudio de José Antonio Rodríguez Garrido (2005).

Aparte de los trabajos citados, tenemos muchos más — no es nuestro propósito reseñarlos todos- que refieren de manera sucinta a la existencia del manuscrito inédito de La segunda parte del Parnaso Antártico, o que ofrecen breves datos del autor y su participación en la Academia Antártica. A continuación, una lista general, por orden cronológico:

1. George Ticknor, en su Historia de la literatura española, hace referencia al autor y a la primera parte del Parnaso Antártico (1854: $242,531)$.

2. Ricardo Palma, en su trabajo titulado Flor de academias y Diente del Parnaso, hace alusión a la primera parte del Parnaso Antártico (1899: 11-14).

3. Rafael de la Fuente Benavides en su trabajo titulado De lo Barroco en el Perú (1938, año de la sustentación de su tesis doctoral). Refiere a ambas partes del Parnaso Antártico, de manera general (1968: 24).

4. Antonio Alatorre, en la «Introducción» a las Heroidas, de Publio Ovidio Nasón, refiere a ambas partes del Parnaso Antártico (1950: 41, nota 43).

5. Aurelio Miró Quesada, en su libro El primer Virrey-poeta en América, menciona ambas partes del Parnaso Antártico (1962: 85).

6. Antonio Cornejo Polar realizó un estudio y edición del «Discurso en loor de la poesía» en 1962. En este trabajo, se centra en la pri- 
https://doi.org/10.46744/bapl.202001.004

mera Parnaso Antártico, aunque también alude a la segunda parte (2000: 55).

7. Guillermo Lohmann Villena menciona a Diego Mexía de Fernangil y sus obras en sendos trabajos, por ejemplo, en el artículo titulado «La academia del príncipe de Esquilache. (Una ficción novelesca)» (1984: 157-58) y, también, en su trabajo titulado «Huellas renacentistas en la literatura peruana del siglo XVI» (1999: 125-26).

8. Trinidad Barrera López ha dedicado sendos estudios a la obra de Diego Mexía de Fernangil, por citar algunos, «La Primera Parte del Parnaso Antártico de Diego Mexía de Fernangil, Sevilla, 1608» (1985). Luego, Barrera presenta un estudio preliminar a la edición facsimilar de la Primera parte del Parnaso Antártico (1990). También, en su trabajo titulado «De academias, transterrados y parnasos antárticos» (2016), alude a ambas partes del Parnaso Antártico.

9. Lucrecio Pérez-Blanco, en su trabajo ««Discurso en loor de la poesía». El otro lazarillo ético-estético de la literatura hispanoamericana del siglo XVII» (1990), refiere a ambas partes del Parnaso Antártico.

10. Consuelo Varela Bueno alude a ambas partes del Parnaso Antártico en los siguientes trabajos: «La Villa Imperial de Potosí: La Babilonia Americana» (2010) y «El magnetismo de Potosí. La Babilonia Americana» (2000).

11. Raquel Chang-Rodríguez ha dedicado los siguientes estudios a la Primera parte del Parnaso Antártico, en los que también refiere a la existencia del manuscrito de la segunda parte: «Ecos andinos: Clarinda y Diego Mexía en la primera Parte del parnaso antártico (1608)» (2003: 67), Clarinda y Amarilis. Discurso en loor de la poesía. Epístola a Belardo (2009: 16, nota [7]), «La lírica en la Lima virreinal: Clarinda y el Discurso en loor de la poesía (1608)» (2011: 91, nota [2]). 
https://doi.org/10.46744/bapl.202001.004

12. Víctor Infantes refiere a ambas partes del Parnaso Antártico en su trabajo titulado «A las poéticas cumbres coronadas la orogelatría impresa del Parnaso áureo» (2011).

13. Juan Gil Fernández refiere a ambas partes del Parnaso Antártico, aunque se centra principalmente en la primera, en su trabajo titulado «Diego Mexía de Fernangil, un perulero humanista en los confines del mundo» (2008).

14. Tatiana Alvarado Teodorika, en su artículo titulado «Mexía de Fernangil: lector y creador de las Heroidas ovidianas. Itinerario de un traductor» (2009), alude al manuscrito de La segunda parte del Parnaso Antártico de divinos poemas.

15. Pablo Luis Quisbert Condori, en su trabajo titulado «Delio en el argénteo monte: nuevos datos en torno a la vida de Diego Mexía de Fernangil en la Villa Imperial de Potosí» (2011), da a conocer varios documentos — desconocidos hasta ese momento- pertenecientes al Archivo Histórico de la Casa de la Moneda de Potosí, que narran detalles sobre la vida de Diego Mexía en Potosí, incluso pormenores de su muerte acaecida en 1634. Puede leerse, también, su otro estudio: «El castigo divino. La destrucción de Anco-Anco (Charcas siglo XVI)», donde Quisbert dice que ha trabajado con una copia del manuscrito proporcionada por Tatiana Alvarado (2016: 42, nota 2).

16. Concepción Reverte Bernal señala que la égloga titulada «El Dios Pan» de La segunda parte del Parnaso Antártico de divinos poemas es un auto sacramental en el contexto del teatro criollo virreinal peruano (2017: 221).

\section{Otras referencias bibliográficas (Catálogos, diccionarios, compendios, antologías, etc.)}

Las alusiones a la primera y/o segunda parte del Parnaso Antártico son numerosas en los diccionarios, antologías, etc. Señalamos las más relevantes, ya sea por su antigüedad o por la importancia de la publicación. 
https://doi.org/10.46744/bapl.202001.004

1. 1783-1788: La cita más temprana de la Primera parte del Parnaso Antártico está en la Bibliotheca hispana nova, de Nicolás Antonio (1783: 299). Riva-Agüero (1914) la señala.

2. 1778: Juan Antonio Pellicer, en su libro Ensayo de una biblioteca, menciona la Primera parte del Parnaso Antártico y alude a la promesa de publicación de la segunda desde las mismas declaraciones de Diego Mexía de Fernangil (1778: 56-58). Riva-Agüero (1914) la señala.

3. 1791: Fermín Arana de Varflora, en Hijos de Sevilla ilustres en santidad, letras armas, artes o dignidad (1791: 85), cita la primera parte; $\mathrm{y}$, en el caso de la segunda hay una imprecisión ya señalada por Riva-Agüero; la cita ad pedem literae es la siguiente:

Fermín Arana de Varflora tiene por dos poetas distintos a Diego Mexía, autor de la Primera parte del Parnaso Antártico, impresa en Sevilla el año de 1608, y a Diego Mexía de Fernangil, autor de los sonetos intitulados Cristi Domini philantropia, que, sin indicación de año, afirma haber impreso igualmente en Sevilla, según el testimonio de Cuesta en sus adiciones a la Biblioteca de Nicolás Antonio [...] No creemos improbable la existencia de tal edición [Cristi Domini philantropia], atendiendo a las palabras de Mexía en su proemio [...] pero es insegurísimo el dato consignado por Varflora, no solo a causa de la fuente que alega y que no hemos podido compulsar, sino por la impresión del título, evidentemente, alterado al verterlo al latín por la ausencia total de indicación de época y porque en ningún caso pudieron ser 163 sonetos publicados, sino 153, que fueron los primitivamente compuestos para servir de comentario a las estampas sobre la vida de Cristo del jesuíta Jerónimo Natal. (Riva-Agüero 1914: 385, 398)

Riva-Agüero (1914: 385) también alude a Lasso de la Vega (1871), quien repite los datos proporcionados por Varflora.

4. 1871: Lasso de la Vega, en su Historia y juicio crítico de la escuela poética sevillana en los siglos XVI y XVII, además de los datos antes señalados y siguiendo las aseveraciones de Varflora, afirma que 
https://doi.org/10.46744/bapl.202001.004

Diego Mexía de Fernangil sería el poeta alabado por Miguel de Cervantes en El viaje del Parnaso (1614):

Sin duda debe ser este Mejía el que Cervantes nombra en su Viaje del Parnaso, como uno de los poetas defensores del imperio de Apolo.

Hacer milagros en el trance piensa

Cepeda, y acompáñalo Mejía:

Poetas dinos de alabanza inmensa.

Este ingenio pertenece, pues, a la época feliz de la poesía hispalense. (Lasso de la Vega y Argüelles, 1871: 276)

Sobre esta posibilidad apuntada por Lasso de la Vega, debemos reconocer que los versos cervantinos, como dice Miró Quesada, "pasan, sin un relieve definido, y con perfiles que llegan a hacerse hasta brumosos por la imprecisa equiparación de los elogios, poetas de España y de las Indias» (1948: 89). Para Miró Quesada, en El viaje del Parnaso (1614), solo hay dos poetas relacionados con el Perú: Pedro de Montes de Oca y Pedro de Oña (1948: 89).

5. 1885: Manuel de Mendiburu, en su Diccionario histórico-biográfico del Perú, menciona a Diego Mexía como autor de la primera parte del Parnaso Antártico; además, cita algunos homónimos coetáneos (1885: 226-27).

6. 1896: Gabriel René Moreno, en su Biblioteca peruana (1896: 428-29), hace referencia solo a la primera parte del Parnaso Antártico.

7. 1910: Carlos Prince, en su Bosquejo de la literatura peruana colonial (1910: 126, 223), menciona solo la primera parte del Parnaso Antártico.

8. 1923: Mario Méndez Bejarano, en su Diccionario de escritores, maestros y oradores naturales de Sevilla y su actual provincia (1923: 70-71), hace mención a la primera y la segunda parte del Parnaso Antártico. 
9. 1935: Rubén Vargas Ugarte, en Manuscritos peruanos en las bibliotecas del extranjero (1935: 73-93), describió y transcribió parte del manuscrito de La segunda parte del Parnaso Antártico. Años después, ubicó la égloga «El Dios Pan» dentro del teatro colonial, cuando la publicó dentro de su colección de piezas dramáticas peruanas de los siglos XVI-XVII y XVIII (1943: 1-26). Esta misma colección fue reeditada en 1974 (1974: 48-70).

10. 1938: Ventura García Calderón elaboró una antología de textos religiosos titulada Los místicos (1938b: 7, 45-83), en la cual transcribe algunos poemas de La segunda parte del Parnaso Antártico.

11. 1957: Alejandro Romualdo y Sebastián Salazar Bondy, en su $A n$ tología general de la poesía peruana (1957: 229), hacen mención a La segunda parte del Parnaso Antártico.

12. 1961: Lino Gómez Canedo, en su libro Los archivos de la bistoria de América. Período colonial español (1961: 256-57), elaboró un catálogo de los manuscritos de interés americano que se encuentran en importantes repositorios franceses. Gómez informó acerca de la existencia del manuscrito de La segunda parte del Parnaso Antártico en la Biblioteca Nacional de Francia.

13. 1966: Emilia Romero, en su Diccionario de literatura peruana (1966: 207), cita ambas partes del Parnaso Antártico.

14. 1984: Ricardo Silva-Santisteban, en su compilación De la conquista al modernismo (1984: 90, 102-19), reproduce la dedicatoria en verso a don Diego de Portugal (presidente en la Real Audiencia de los Charcas). Esta antecede a la conocida égloga titulada «El Dios Pan».

15. 1990: César Toro Montalvo, en su Manual de literatura peruana (2000, 1. ${ }^{a}$ ed. de 1990: 176-77), transcribe dos sonetos de la Vida de Cristo de La segunda parte del Parnaso Antártico. Estos poemas son el soneto 11 y el soneto que está luego del 175, pero que no tiene 
https://doi.org/10.46744/bapl.202001.004

numeración en el manuscrito. Toro Montalvo, asimismo, menciona la obra poética de Diego Mexía de Fernangil en su Historia de la literatura peruana (1994: 184), en el volumen dedicado a la Colonia. En este trabajo no reproduce ningún poema de Diego Mexía de Fernangil.

16. 2000: García-Bedoya Maguiña, en su libro titulado La literatura peruana en el periodo de estabilización colonial, ubica La segunda parte del Parnaso Antártico dentro de la poesía religiosa. Destaca que esta obra es una muestra de «renacentismo declinante y barroco emergente» (2000: 84) en el contexto de las denominadas «vertientes del discurso criollo». También, García-Bedoya, en la cronología que traza entre literatura y sociedad (2000: 240), ubica este manuscrito en 1617 del mismo modo que en su estudio Para una periodización de la literatura peruana (2004: 112).

Finalmente, subrayamos que estas no son todas las referencias ni ha sido nuestra intención cubrir todas las citas en torno a Diego Mexía de Fernangil y La segunda parte del Parnaso Antártico, sino mostrar cómo esta obra y su autor no fueron ajenos — ni mucho menos desconocidos- a la crítica literaria de los últimos siglos.

\section{La transcripción mecanografiada del manuscrito único existente en la Biblioteca Nacional del Perú}

Luis Jaime Cisneros - en la reproducción de los sonetos 146 y 155 de la «Vida de Cristo» de La segunda parte del Parnaso Antártico — dice lo siguiente: «Me valgo de la fotocopia que se halla en la Biblioteca Nacional de Lima» (1951: 70). En esta nota, el lingüista no permite establecer con claridad si se trata de una fotocopia del manuscrito de París ${ }^{4}$ o de la fotocopia de una transcripción mecanografiada del manuscrito. En la Biblioteca Nacional de Lima solo se encuentra esto último. No obstante, las aclaraciones que L. J. Cisneros da a continuación en la misma nota harían suponer que,

4 Luis Alberto Sánchez, en su libro Los poetas de la Colonia y la Revolución (3.a ed.), indica que «Hay una copia fotostática en la Biblioteca Nacional de Lima. (Nota de 1946)» (1974: 64, nota 3). 
https://doi.org/10.46744/bapl.202001.004

en aquella ocasión, trabajó con una fotocopia del manuscrito original (la alusión a las «s» largas), la cual actualmente habría sido suplantada por la referida transcripción mecanografiada:

Dejo constancia de mi agradecimiento al señor Roberto Villarán Koechlin, mi alumno en el Instituto Riva Agüero, que me ayuda en la transcripción de la obra de Mexía. He resuelto en la edición las «s» largas. En el soneto 155, reemplazo la «c con cedilla» del original por «z», por razones tipográficas (empieza, enlaza, traza). (Luis Jaime Cisneros, 1951: 70)

La transcripción mecanografiada del manuscrito llega hasta el folio $102 r^{\circ}$. Se encuentra bajo la signatura B202. En el catálogo de la Biblioteca Nacional aparece como «Fecha de inicio 19/1/1649». No se indica el autor de la transcripción mecanográfica.

\section{Publicaciones parciales de La segunda parte del parnaso antártico de divinos poemas}

No hay, hasta la fecha, una edición completa de este manuscrito. José Toribio Medina reproduce fragmentos de la dedicatoria al príncipe de Esquilache y el prólogo al lector (1878: 196-197 y 1900: 91). Marcelino Menéndez y Pelayo reproduce, igualmente, fragmentos de la dedicatoria al príncipe de Esquilache y el prólogo al lector (1895b: 108-109). José de la Riva-Agüero (1914) es el que más fragmentos reprodujo: texto de la carátula, parcialmente la dedicatoria al príncipe de Esquilache, epígrafes en latín, el índice, parcialmente el prólogo al lector, fragmentos de la introducción a la obra, sonetos $8,10,41,110,182$, soneto 129 (dos tercetos), soneto 136 (dos tercetos), soneto 137 (dos tercetos), soneto 144 (las dos primeras estrofas), soneto 167 (dos tercetos), soneto 175 (dos tercetos), soneto sin número (le sigue al soneto $175,88 \mathrm{v}^{\circ}$ ), soneto 189 (dos tercetos), el soneto 192 (un terceto), soneto y peroración, fragmentos de la «Epístola a la Virgen María» (102v. $\left.{ }^{\circ}, 114 \mathrm{v}^{\circ}, 116 \mathrm{v}^{\circ}, 117 . \mathrm{r}^{\circ}\right)$, fragmentos de la «Vida de santa Margarita» $\left(118 \mathrm{v}^{\circ}, 124,128 \mathrm{v} .^{\circ}, 131 \mathrm{r}^{\circ},{ }^{\circ}, 137 \mathrm{r}^{\circ}{ }^{\circ}\right)$, fragmentos de la «Oración en alabanza de santa Ana» (138v. $\left.{ }^{\circ}, 139 v^{\circ}, 144 v^{\circ}, 145 \mathrm{r}^{\circ}\right)$, fragmentos de la égloga «El Buen Pastor» $\left(162 \mathrm{v}^{\circ}, 164 \mathrm{v}^{\circ}, 169 \mathrm{r} .{ }^{\circ}\right)$, casi completa la dedicatoria a Diego de Portugal (presidente de la Audiencia 
de Charcas), que antecede a la égloga «El Dios Pan» (169v. $\left.{ }^{\circ}-181 \mathrm{r}^{\circ}\right)$; fragmentos de los villancicos de la égloga «El Dios Pan» (186r. ${ }^{\circ}, 187 v^{\circ}$, 188 v. $^{\circ}, 191$ r. $^{\circ}, 195$ r. $^{\circ}$.

Rubén Vargas Ugarte reproduce el texto de la portada, Índice, epígrafes latinos, el soneto titulado «A Cristo Nuestro Señor», ante la estampa de Anthoine Wiericx, los seis primeros versos de la introducción a la obra, soneto de la peroración a la «Vida de Cristo», la «Vida de santa Margarita» (los primeros 19 versos), los versos de la «Oración en alabanza de santa Ana» que se encuentran en los folios $138 \mathrm{v}^{\circ}, 139 \mathrm{v}^{\circ}$ y $140 \mathrm{v} .^{\circ}$, de la égloga «El Buen Pastor» el fol. 162r. ${ }^{\circ}$ y parte del fol. 162v. ${ }^{\circ}$, y los 13 últimos versos, la égloga «El Dios Pan» y la dedicatoria que le precede. (1935: 73-93 y 1943: 1-26).

Ventura García Calderón reproduce los sonetos 6, 7, 11, 33, 170, 171, 173, sin número, 179, 180 y 182, «Epístola a la Virgen María», los 104 primeros versos «Memorare, novísima» (1938: 45-83). Luis Jaime Cisneros reproduce los sonetos 146, 155 y el de la peroración de la «Vida de Cristo» (1951: 70 y 1953: 71). Ricardo Silva-Santisteban reproduce la epístola y dedicación a don Diego de Portugal, que antecede a la égloga «El Dios Pan» (1984: 102-119). César Toro Montalvo reproduce los sonetos 11 y el soneto sin número de la «Vida de Cristo» (2000: 176-177). José Antonio Rodríguez Garrido (2005: 311-314) reproduce fragmentos de la dedicatoria que antecede a la égloga «El Dios Pan» y también los primeros versos de la misma égloga (Fols. 169v. ${ }^{\circ}, 170{ }^{\circ}{ }^{\circ}, 172$ r. $^{\circ}, 172 v^{\circ}$, $176 v^{\circ}, 180 \mathrm{r}^{\circ}, 180 \mathrm{v}^{\circ}$ y $181 \mathrm{v}^{\circ}{ }^{\circ}$. Alicia de Colombí-Monguió reproduce fragmentos del prólogo, el penúltimo terceto del soneto 8 , los sonetos 4 , 26, 181 y 182 de la «Vida de Cristo», tres últimos tercetos del folio $113 \mathrm{v} .{ }^{\circ}$ correspondientes a la «Epístola a la Virgen María» (2009: 68-77). Paola Coronado-Gálvez reproduce la égloga El Buen Pastor» (2010: 43-47). Bernat Castany Prado reproduce fragmentos de la dedicatoria al príncipe de Esquilache y el prólogo al lector, los seis primeros versos de la introducción a la obra (fol. $\mathrm{mv}^{\circ}$ ), sonetos $8,11,25$, soneto 41 (un terceto), soneto 52 (un terceto), soneto 110 (un terceto), soneto sin número (fol. 88v. ${ }^{\circ}$ ), penúltimo terceto del soneto y peroración, la «Vida de santa Margarita» (los dos primeros tercetos), tercer terceto del fol. $173 \mathrm{r}^{\circ}$ correspondiente a 
la «Epístola y dedicación a don Diego de Portugal» que precede a la égloga «El Dios Pan» (2015: 66-84). Pablo Luis Quisbert Condori reproduce parcialmente los tres últimos tercetos del folio $177 \mathrm{r} .{ }^{\circ}$ correspondientes a la «Epístola y dedicación a don Diego de Portugal» que precede a la égloga «El Dios Pan» (2016: 42).

\section{Conclusiones}

1. Llama la atención que un texto tan comentado y estudiado de modo directo o indirecto no se haya publicado hasta la fecha. No existe una edición completa de la obra.

2. La autora de este artículo está presentando a la sección doctoral de la Universidad Nacional Mayor de San Marcos una tesis que comprende la transcripción del manuscrito y una edición modernizada, acompañadas de un breve estudio literario del cual se extrajo el contenido de este artículo.

3. Será posible realizar nuevos estudios con estas ediciones ahora sustentados en el conocimiento completo del texto de esta obra. 
https://doi.org/10.46744/bapl.202001.004

\section{BIBLIOGRAFÍA}

ALATORRE, A. (1950). Introducción. Heroidas de Publio Ovidio Nasón. Ciudad de México: Universidad Nacional Autónoma de México.

ALVARADO T., T. (2009). Mexía de Fernangil: lector y creador de las Heroidas ovidianas. Itinerario de un traductor. La Clé des langues (en ligne).

ANTONIO, N. (1783). Bibliotheca hispana nova. Vol. 1. Madrid: Ibarra.

ARANA DE VARFLORA, F. (1791). Hijos de Sevilla: Ilustres en santidad, letras, armas, artes, o dignidad. Vol. 1. Sevilla: Impr. de Vazquez e Hidalgo.

BARRERA L., T. (1985). La Primera Parte del Parnaso Antártico de Diego Mexía de Fernangil, Sevilla, 1608. Actas de las III Jornadas de Andalucía y América, pp. 213-29. Sevilla: Escuela de Estudios Hispano-Americanos.

. (1990). Introducción. Primera parte del Parnaso Antártico de obras amatorias, por Diego Mexía (Edición facsimilar), editado por T. Barrera, pp. 8-34. Roma: Bulzoni Editore.

. (2016). De academias, transterrados y parnasos antárticos. América sin Nombre, 14(13-14): 15-21.

BERNASCHINA S., V. (2019). Ángeles que cantan de continuo. La legitimación teológica de la poesía en el virreinato del Perú. 1. ${ }^{a}$ ed. Potsdam: Universitätsverlag Potsdam.

CASTANY P., B. (2015). «Ovidio transformado». La presencia de Ovidio en las dos primeras partes del «Parnaso Antártico» de Diego Mexía de Fernangil», Clásicos para un Nuevo Mundo. Estudios sobre la tradición clásica en la América de los siglos XVI y XVII, 
https://doi.org/10.46744/bapl.202001.004

editado por G. Bernat, pp. 58-85. Barcelona: Centro para la edición de los clásicos españoles.

CEJADOR Y FRAUCA, J. (1916). Historia de la lengua y literatura castellana. Época de Felipe III. Vol. 4. Madrid: Tip. de la Revista de Archivos, Bibliotecas Museos.

CERVANTES S., M. (1614). Viaje del Parnaso. Madrid: por la viuda de Alonso Martín.

CHANG-RODRÍGUEZ, R. (2003). Ecos andinos: Clarinda y Diego Mexía en la primera Parte del parnaso antártico (1608). Calíope, 9(1).

. (2009). Clarinda y Amarilis. Discurso en loor de la poesía. Epístola a Belardo. Lima: Pontificia Universidad Católica del Perú.

. (2011). La lírica en la Lima virreinal: Clarinda y el Discurso en loor de la poesía (1608). Guaraguao. Revista de Cultura Latinoamericana, (36).

CISNEROS, L. (1951). Diego Mexía de Fernangil. Mar del Sur, VI(17). . (1953). Soneto de Diego Mexía. Mar del Sur, (28).

COLOMBÍ-MONGUIÓ, A. (2009). Estudio preliminar. Lecturas paralelas: La musa sagrada en Potosí. Luis de Ribera. Sagradas poesías, editado por L. García Pabón, pp. 67-107. La Paz: Plural Editores.

CORNEJO P., A. (2000). Discurso en loor de la poesía: estudio y edición. editado por A. de Colombí-Monguió, L. J. Cisneros, y J. A. Mazzotti. Lima: Centro de Estudios Literarios «Antonio Cornejo Polar»-Latinoamericana Editores.

CORONADO-GÁlVEZ, P. (2010). Diego Mexía de Fernangil, un poeta antártico. Boletín Hispánico Helvético. Universidad de Ginebra-Sociedad Suiza de Estudios Hispánicos, 15-16: 31-49. 
https://doi.org/10.46744/bapl.202001.004

DELGADO, W. (2002). Literatura colonial. De Amarilis a Concolocorvo. Lima: San Marcos.

DE LA FUENTE, R. (1968). De lo Barroco en el Perú. editado por E. Bendezú Aibar. Lima: Universidad Nacional Mayor de San Marcos.

GARCÍA-BEDOYA, C. (2000). La literatura peruana en el periodo de estabilización colonial. Lima: Universidad Nacional Mayor de San Marcos.

. (2004). Para una periodización de la literatura peruana.

2. ${ }^{a}$ ed. Lima: Universidad Nacional Mayor de San Marcos.

GARCÍA CALDERÓN, V., ed. (1938a). Apogeo de la literatura colonial. Las poetisas anónimas, el Lunarejo, Caviedes. París: Desclée de Brouwer.

, ed. (1938b). Los místicos. París: Desclée de Brouwer.

GIL, J. (2008). Diego Mexía de Fernangil, un perulero humanista en los confines del mundo. El humanismo español entre el viejo mundo y el nuevo, editado por J. M. Nieto Ibáñez y R. Manchón Gómez, pp. 67-141. Salamanca.

GÓMEZ C., L. (1961). Los archivos de la historia de América. Período colonial español. México D. F.: Instituto Panamericano de Geografía e Historia.

INFANTES, V. (2011). A las poéticas cumbres coronadas la orogelatría impresa del Parnaso áureo. Bulletin Hispanique, (109).

LASSO DE LA VEGA Y ARGÜELLES, Á. (1871). Historia y juicio crítico de la escuela poética sevillana en los siglos XVI y XVII. Madrid: Imprenta de la viuda e hijos de Galiano; Ministerio de Fomento. 

https://doi.org/10.46744/bapl.202001.004

LOHMANN V., G. (1951). Alcances biográficos. Mar del Sur, 6(17), pp. 47-55.

. (1984). La Academia del príncipe de Esquilache. (Una ficción novelesca). Boletín del Instituto Riva-Agüero, 13, pp. 151-62.

. (1999). Huellas renacentistas en la literatura peruana del siglo XVI. La tradición clásica en el Perú virreinal, editado por T. Hampe, pp. 115-27. Lima: Universidad Nacional Mayor de San Marcos.

MEDINA, J. (1878). Historia de la literatura colonial de Chile. Vol. 1. Santiago de Chile: Libería del Mercurio.

. (1900). Biblioteca Hispano-americana (1601-1650). Vol. 2. Santiago de Chile: Impreso y grabado en la casa del autor.

MÉNDEZ B., M. (1923). Diccionario de escritores, maestros y oradores naturales de Sevilla y su actual provincia. Vol. 2. Sevilla: Tipografía Gironés, O’Donnell.

MENDiBURU, M. (1885). Diccionario histórico-biográfico del Perú. Parte primera que corresponde a la época de la dominación española. Vol. 5. Lima: Imprenta Bolognesi.

MENÉNDEZ Y PELAYO, M. (1895a). Antología de poetas hispano-americanos. Vol. 4. Madrid: Real Academia Española.

. (1895b). De los poemas históricos relativos a Chile. $L a$ España Moderna, 7(73), pp. 97-125.

. (1913). Historia de la poesía hispano-americana. Vol. 2. editado por Victoriano Suárez. Madrid: Victoriano Suárez.

MEXÍA DE FERNANGIL, D. (1608). Primera parte del Parnaso Antártico de obras amatorias. Sevilla: por Alonso Rodríguez Gamarra. 
https://doi.org/10.46744/bapl.202001.004

. (1617). La segunda parte del Parnaso Antártico de divinos poemas. Potosí.

MIRÓ Q., A. (1948). Cervantes, Tirso y el Perú. Lima: Huascarán.

. (1962). El primer virrey-poeta en América. (Don Juan de Mendoza y Luna, Marqués de Montesclaros). Madrid: Gredos.

MOREL-FATIO, A. (1892). Catalogue des manuscrits espagnols et des manuscrits portugais. París: Biblioteca Nacional-Departamento de Manuscritos.

MORENO, G. (1896). Biblioteca peruana: Apuntes para un catálogo de impresos. Vol. 2. Santiago de Chile: Biblioteca Nacional.

OCHOA G., C. (1959). Bio-bibliografía de Diego Mexía de Fernangil. 101.

PACHECO V., C. y A. VARILLAS, eds. (1962). Obras completas de José de la Riva Agüero. Del Inca Garcilaso a Eguren. Vol. 2. Lima: Pontificia Universidad Católica del Perú.

PALMA, R., ed. (1899). Flor de academias y Diente del Parnaso. Lima, Perú: Jiménez, L. H.

PELLICER Y SAFORCADA, J. (1778). Ensayo de una bibliotheca de traductores españoles. Madrid: Antonio de Sancha.

PÉREZ-BLANCO, L. (1990). «Discurso en loor de la poesía». El otro lazarillo ético-estético de la literatura hispanoamericana del siglo XVII. Quinto Centenario. Vol. 16, pp. 210-37. Madrid: Universidad Complutense de Madrid.

PRINCE, C. (1910). Bosquejo de la literatura peruana colonial. Causas favorables y adversas a su desarrollo. Lima: Impreso en casa del autor. 
https://doi.org/10.46744/bapl.202001.004

PROYECTO ESTUDIOS INDIANOS. Segunda parte del Parnaso antártico de divinos poemas, de Diego Mejía Fernangil. Disponible en http://estudiosindianos.org/biblioteca-indiana/ segunda-parte-del-parnaso-antartico-de-divinos-poemas/. Consultado el 15 de noviembre de 2019.

QUISBERT C., P. (2011). Delio en el argénteo monte: nuevos datos en torno a la vida de Diego Mexía de Fernangil en la Villa Imperial de Potosí. Alpha, (33), pp. 257-72.

. (2016). El castigo divino. La destrucción de Anco-Anco (Charcas siglo XVI). Iberoamericana. América Latina - España Portugal, 16(61), pp. 37-50.

REVERTE B., C. (2017). El teatro criollo. Literatura y cultura en el Virreinato del Perú: apropiación y diferencia, editado por R. Chang-Rodríguez y C. García-Bedoya, pp. 211-45. Lima: Pontificia Universidad Católica del Perú, Casa de la Literatura, Ministerio de Educación del Perú.

RIVA-AGÜERO, J. (1914). Diego Mexía de Fernangil, poeta sevillano del siglo XVI, avecindado en el Perú y la segunda parte de su Parnaso Antártico, existente en la Biblioteca Nacional de París. Actas y memorias del Congreso de Historia y Geografía Hispanoamericana, pp. 385-427. Madrid: Establecimiento Tipográfico de Jaime Ratés.

RODRÍGUEZ G., J. (2005). La égloga el Dios Pan de Diego Mexía de Fernangil y la evangelización en los Andes a inicios del siglo XVII. Manierismo y transición al barroco. Memoria del III Encuentro Internacional sobre Barroco, pp. 307-19. Navarra: Fundación Visión Cultural/Servicio de Publicaciones de la Universidad de Navarra.

ROMERO, E. (1966). Diccionario de literatura peruana y materias afines. Universidad Nacional Mayor de San Marcos. 
https://doi.org/10.46744/bapl.202001.004

ROMUALDO, A. y S. SALAZAR BONDY. (1957). Antología general de la poesía peruana. Lima: Librería Internacional del Perú.

SÁNCHEZ, L. (1965). La literatura peruana. Derrotero para una historia cultural del Perú. Vol. 2. Lima, Perú: Ediventas.

. (1974). Los poetas de la Colonia y de la Revolución. 3. ${ }^{\mathrm{a}} \mathrm{ed}$. Lima, Perú: Editorial Universo.

SILVA-SANTISTEBAN, R. ed. (1984). De la conquista al modernismo. Poesía peruana. Antología general. Vol. 2. Lima: Ediciones Edubanco.

SUÁREZ-MIRAVAL, M. (1959). La poesía en el Perú. Desde los quechuas hasta Enrique Garcés. Lima: Tawantinsuyo.

TAMAYO VARGAS, A. (1947). Apuntes para un estudio de la literatura peruana. Lima.

. (1968). Literatura peruana. Vol. 1, 3. . ed., editado por J. Godard. Lima: Talleres Gráficos Iberia.

TAURO DEL PINO, A. (1948). Esquividad y gloria de la Academia Antártica. Lima: Editorial Huascarán.

TICKNOR, G. (1854). Historia de la literatura española. Vol. 3. Madrid: M. Rivadeneyra.

TORO M., C. (1994). Historia de la literatura peruana. Vol. 2. Lima: A.F.A. Editores Importadores.

. (2000). Manual de literatura peruana. Vol. 1, 4. ${ }^{\mathrm{a}}$ ed. Lima: A.F.A. Editores Importadores.

VALBUENA, Á. (1960). Historia de la literatura española. Vol. 1, 6. ${ }^{\text {a ed. }}$ Lima: Gustavo Gili. 

https://doi.org/10.46744/bapl.202001.004

VARELA B., C. (2000). «El magnetismo de Potosí. La Babilonia Americana», pp. 175-89 en Potosí. Plata para Europa, editado por J. Marchena. Sevilla: El Monte.

. (2010). «La Villa Imperial de Potosí: La Babilonia Americana». La ciudad americana: mitos, espacios y control social, editado por A. S. Bernabéu y C. Varela Bueno, pp. 133-48. Ediciones Doce Calles.

VARGAS U., R. (1935). Manuscritos peruanos en las bibliotecas del extranjero. Vol. 1. Lima: Taller tipográfico de la Empresa Periodística La Prensa.

, ed. (1943). De nuestro antiguo teatro. Colección de piezas dramáticas de los siglos XVI-XVII y XVIII. Lima: Compañía de Impresiones y Publicidad Enrique Bustamante y Ballivián.

VARGAS U., R. y C. MILLA BATRES, eds. (1974). De nuestro antiguo teatro. Colección de piezas dramáticas de los siglos XVI-XVII y XVIII. Lima: Editorial Jurídica. 